\title{
Correction: Oleas, N.H., et al. Muddy Boots Beget Wisdom: Implications for Rare or Endangered Plant Species Distribution Models. Diversity, 2019, 11, 10
}

\author{
Nora H. Oleas ${ }^{1,2,3, *}$, , Kenneth J. Feeley ${ }^{4}$, Javier Fajardo ${ }^{5,6} \oplus^{\circ}$, Alan W. Meerow ${ }^{7,8}$, \\ Jennifer Gebelein ${ }^{9}$ and Javier Francisco-Ortega ${ }^{2,3}$ \\ 1 Centro de Investigación de la Biodiversidad y Cambio Climático, y Carrera de Ingeniería en Biodiversidad \\ y Recursos Genéticos, Facultad de Ciencias del Medio Ambiente, Universidad Tecnológica Indoamérica, \\ Machala y Sabanilla, Quito EC170301, Ecuador \\ 2 Department of Biological Sciences, International Center for Tropical Botany, Cuban Research Institute, \\ and Kimberly Green Latin American and Caribbean Center, Florida International University, Miami, \\ FL 33199, USA; ortegaj@fiu.edu \\ 3 Kushlan Tropical Science Institute, Fairchild Tropical Botanic Garden, Coral Gables, Florida, FL 33156, USA \\ 4 Department of Biology, University of Miami, Coral Gables, FL 33146, USA; kjfeeley@gmail.com \\ 5 Centro Universitario de Mérida, Universidad de Extremadura, 06800 Mérida, Spain; \\ javierfajnolla@gmail.com \\ 6 Real Jardín Botánico (RJB-CSIC), 28014 Madrid, Spain \\ 7 Arizona State University, School of Life Sciences, Tempe, AZ 85281, USA; griffinia@gmail.com \\ 8 Montgomery Botanical Center, Coral Gables, FL 33156, USA \\ 9 Department of Earth and Environment, Florida International University, Miami, FL 33199, USA; \\ gebelein@fiu.edu \\ * Correspondence: noraoleas@uti.edu.ec; Tel.: +593-2-382-6970
}

Received: 24 August 2020; Accepted: 9 October 2020; Published: 15 October 2020

\section{Error in Figure}

An error on our paper [1] came to our attention. The reason for the correction is a mistake in Figure 1. The names of the species were switched between P. schizantha and P. dubia. The correct new Figure 1 is shown below: The above error did not change the results and conclusions of our paper. However, the authors would like to apologize for any inconvenience caused to the readers by this error. 
DATABASE

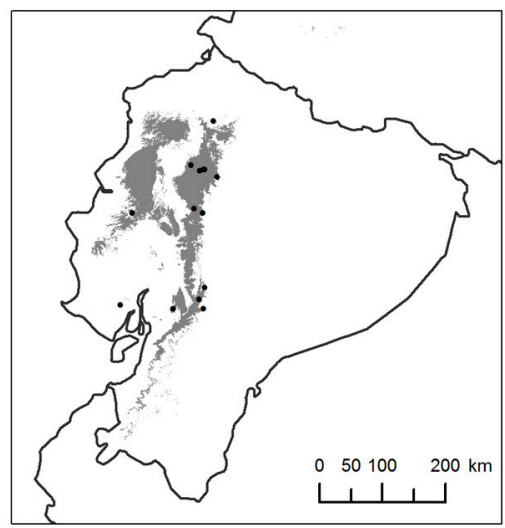

VERIFIED

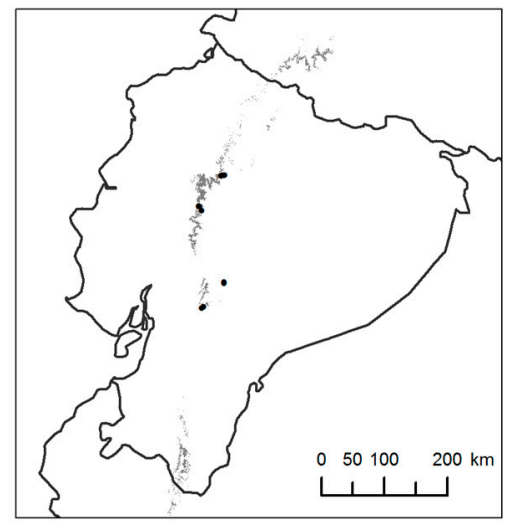

P. cinerea
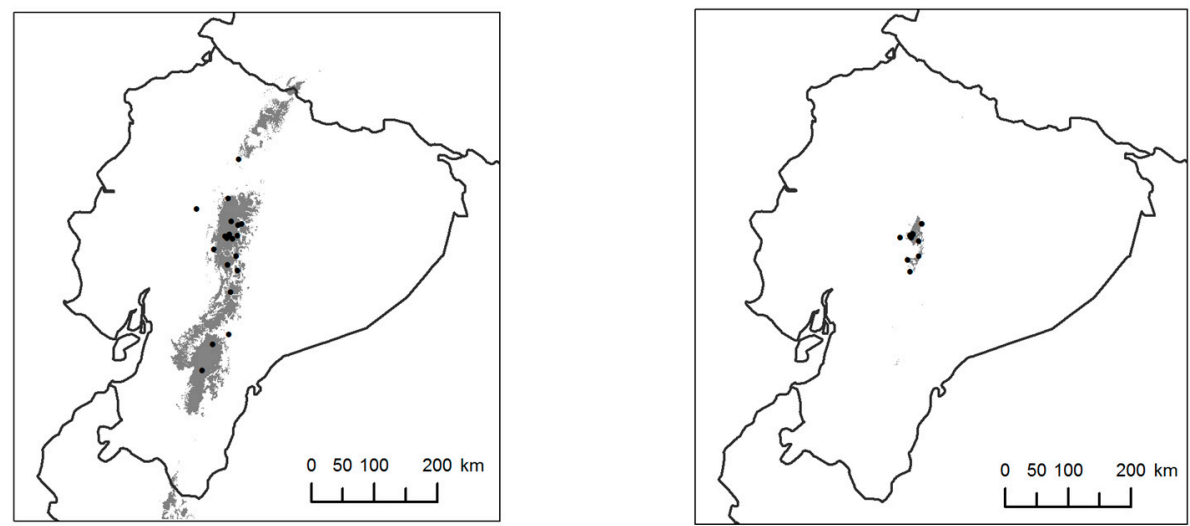

P. schizantha

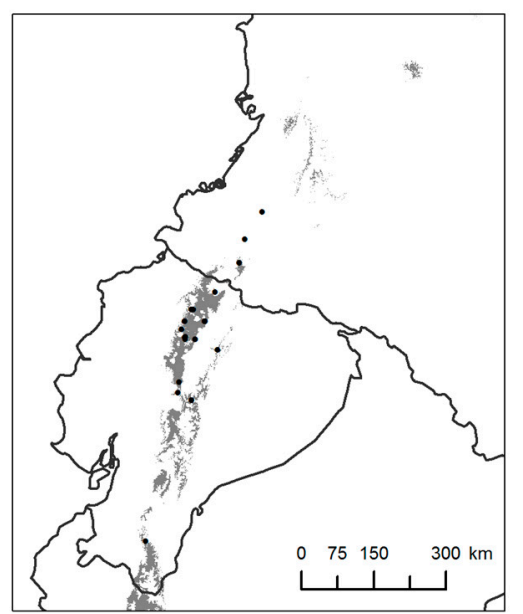

\section{P. dubia}

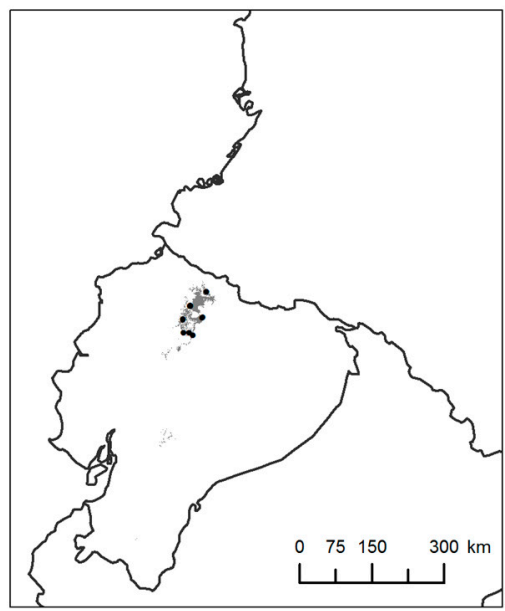

Figure 1. Distribution maps for Phaedranassa cinerea, P. schizantha and P. dubia (Amaryllidaceae) in Ecuador. Darker areas indicate predicted potential ranges based on online database records (left) and verified records (right). Points show the actual species distribution.

Conflicts of Interest: The authors declare no conflict of interest. 


\section{References}

1. Oleas, N.H.; Feeley, K.J.; Fajardo, J.; Meerow, A.W.; Gebelein, J.; Francisco-Ortega, J. Muddy Boots Beget Wisdom: Implications for Rare or Endangered Plant Species Distribution Models. Diversity 2019, 11, 10. [CrossRef]

Publisher's Note: MDPI stays neutral with regard to jurisdictional claims in published maps and institutional affiliations.

(C) 2020 by the authors. Licensee MDPI, Basel, Switzerland. This article is an open access article distributed under the terms and conditions of the Creative Commons Attribution (CC BY) license (http://creativecommons.org/licenses/by/4.0/). 